\title{
The Value of Collective and Individual Assets in Building Urban Community Resilience
}

\section{Wijitbusaba Marome* ${ }^{1}$, Diane Archer ${ }^{2}$, Boonanan Natakun ${ }^{3}$ and Nuttavikhom Phanthuwongpakdee ${ }^{4}$}

${ }^{1}$ Faculty of Architecture and Planning, Thammasat University / Pathumthani, Thailand

${ }^{2}$ Stockholm Environmental Institute / Bangkok, Thailand

${ }^{3}$ Faculty of Architecture and Planning, Thammasat University / Pathumthani, Thailand

${ }^{4}$ Urban Futures Research Unit, Faculty of Architecture and Planning, Thammasat University /

Pathumthani, Thailand

E-Mails: wijitbusaba@ap.tu.ac.th; diane.archer@sei.org; boonanan@ap.tu.ac.th;

manateedugong@gmail.com

* Author to whom correspondence should be addressed; Tel.: +66-93-549-2656

\begin{abstract}
Bangkok, as Thailand's capital, has experienced disruptive flood events and remains vulnerable to sea level rise and subsidence. Those living in low-income communities are often most exposed to climate risk, living along canals, in housing and with infrastructure that is not adapted to climate change. Ensuring that Thai cities plan for resilient and inclusive growth is therefore important for achieving a sustainable urban future. Urban resilience here encompasses not only physical resilience to climate change impacts and other shocks, but also socio-economic resilience, such that vulnerable population groups are not left behind. This paper aims to foster inclusive urban governance which integrates communities' well-being along with considerations of physical environment - including systems of land use, water and solid waste management. The findings highlight how low-income communities prepare for a potential shock such as flooding, drought or an economic crisis. Which individual and collective assets- internal and external - are at risk, and which can be used to overcome those risks? Do residents apply mechanisms of coping, adapting, or something new, and is collective action applied? The data draws from a household survey and interviews across three communities, and an innovative resilience toolkit developed in order to foster community dialogue around what is required to achieve community-based resilience strategies. Known as 'Kin dee you dee' (live well, eat well), the interactive community-level toolkit focuses on seven types of assets
\end{abstract}


used by community residents and their potential for building resilience: water, food, shelter and people, economic resources, community assets, and new resources made from old (for example, by recycling materials). Our findings highlight different approaches to achieving inclusive planning approaches which support both climate resilient and sustainable development pathways at community and city scale - including the potential offered by multi-sectoral, multi-actor responses drawing on private, public and civil society actors and assets.

Keywords: resilience; adaptation; urban; inclusive; urban climate governance; Bangkok; assets

\section{Introduction}

This paper aims to understand how organised urban communities in Bangkok are planning for and responding to environmental and other crises, in order to identify approaches to fostering more sustainable, inclusive and resilient urban development. The Bangkok Metropolitan Region (BMR), an area with a population of 10.07 million (2007) and Thailand's economic and political capital city, is at risk from the impacts of climate change, alongside other environmental hazards including pollution of air and waterways. The BMR has faced such hazards before, notably the 2011 floods, and the likelihood of future such events is high. It is important to ensure that all residents of the BMR are able to prepare for future potential shocks, and that no one gets left behind. For those on lower-incomes, who may not have access to support systems such as disaster insurance, being able to make optimum use of existing assets, at the individual and collective level, can offer an opportunity for successful coping and adaptation strategies in the face of future shocks. Drawing on Stein and Moser (2014), the authors seek to demonstrate that lower-income population groups are already taking actions to cope and adapt using their assets in response to current and future hazards to a certain extent, and that such approaches can be an entry point for cooperation between these communities and other stakeholders, including local government, local NGOs and other institutions.

This paper explores how low-income communities in Bangkok prepare for a potential shock such as flooding, drought or an economic crisis. Which individual and collective assets- internal and external - are at risk, and which can be used to overcome those risks? Do residents apply mechanisms of coping, adapting, or something new, and is collective action applied? The data draws from a household survey and interviews across three communities which have engaged in the government-funded participatory slum upgrading program, Baan Mankong. In particular, the study seeks to answer the following research questions:

1) What are existing adaptive mechanisms of households for crises?

2) Do communities have collective resilience strategies and what role do community assets play?

The research study also led to the testing and development of an innovative resilience toolkit that can be used to foster community dialogue around what is required to achieve community-based resilience strategies. Known as 'Kin dee you dee' (live well, eat well), the interactive community-level toolkit focuses on seven types of assets used by community residents and their potential for building 
resilience: water, food, shelter and people, economic resources, community assets, and new resources made from old (for example, by recycling materials).

Thailand's two extensive coastlines (along the Gulf of Thailand and the Andaman Sea) make large areas of the country susceptible to the impacts of climate change, such as sea level rise and flooding, as has been documented by Marome (2013). Situated along the Gulf of Thailand, the Bangkok Metropolitan Region (BMR) is an economic hub that has already experienced significant flood events and is particularly vulnerable to sea-level rise, compounded by subsidence, in addition to urban heat island effects. People living in low-income communities, especially those who live along canals, are often most exposed as their dwellings and infrastructure are not adapted to climate change. This combination of factors means that ensuring Thai cities plan for resilient and inclusive growth is imperative to sustainable urban future. Unfortunately, such action has not yet transpired (Marome, 2017).

\section{State of the Art}

Building resilience as a concept is increasingly seen as the norm with regards to preparing for and responding to climate change impacts alongside other shocks and stresses. In this paper, we adopt the concept of urban resilience as something which emerges through the roles played by individuals and institutions, as opposed to a solely physical construct determined by physical infrastructure and the environment. As cities face uncertainty, city actors will need to adopt a diversity of approaches, to be flexible to respond to the changes that may arise (Bene et al, 2017). These diverse approaches can be termed 'adaptive governance', which builds on trends for more participatory, decentralised governance, to build capacity for learning, more flexible institutions and different types of knowledge (Baud and Hordijk, 2009). Local governments are a central actor in adaptive urban governance, as they define urban plans and infrastructure investment decisions, though their ability to act will to a certain extent be shaped by central government policies and plans. Thus, recognising that climate change is a challenge which cannot be solely addressed by a single organisation or governance institution, 'multilevel or multiscale governance' (Leck and Simon, 2012) is necessary, which 'implies a recognition of the multiple actors who intervene' (Castan Broto, 2017:1) - a shift away from a topdown, state-led approach towards including actors from both the government and non-government sector, including community groups.

At the level of low-income local communities and households, there is already much evidence of the actions they take in order to cope with and adapt to climate change, in order to minimise the impacts of climatic hazards. Coping mechanisms are distinguished by being reactive and geared towards survival, while adaptation involves planning with a longer-term outlook (CARE, 2009) and therefore should contribute to, rather than deplete, assets. Adaptive mechanisms can range from household-level measures such as retrofitting cyclone-proof roofing in Vietnam (Moench et al, 2017), growing vines on roofs for cooling in Bangladesh (Haque, Dodman and Hossain, 2014) to raising the plinth of homes against flooding, to community-level action such as improving storm drains and paving paths. The types of investments that households and communities are willing to make are in part determined by their land status - security of tenure, particularly ownership of homes, will increase the likelihood of willingness to invest in longer-term adaptive mechanisms (Roy, Hulme and Jahan, 2013). 
Assets are essential to the livelihoods and financial security of low-income households, with asset accumulation contributing towards urban poverty reduction (Moser 2009). With regard to climate change adaptation, approaches to adaptation which support the assets of low-income households can therefore contribute to securing their longer-term future. However, there are limits to what adaptation can be done by individual households or low-income communities without also involving wider urban stakeholders - for example community-level drainage systems and paths need to be integrated to wider trunk infrastructure, and climate impacts locally will be determined by systems managed more widely, such as watersheds. Therefore, effective adaptation requires household and community planning and action be supported by local government, who need to be accountable and responsive to local needs (Satterthwaite et al 2018).

\section{Methods (Apply style M_Heading1)}

We chose to focus our case studies on urban and peri-urban communities which had experience of the collective upgrading program Baan Mankong ('secure housing') - which would indicate experience of collective engagement around communal issues. This national program offers lowinterest collective loans and infrastructure subsidies for participatory upgrading of housing and infrastructure (on-site or by relocation), as well as collective land titling or lease, to organised communities that have established a cooperative through a savings process. Our case studies also had experienced previous shocks like flooding or eviction threats.

Situated in Bang Kaen disctrict in the northern part of Bangkok, Roi Klong community has a typical canal-side community's shape, a narrow and long (20 by 620 meter) strip, lying along an east bank of Bangbua canal. Due to the course of urban expansion towards the north, Roi Klong and other nearby canal-side communities have increasingly faced various problems, such as overcrowding, environmental degradation and other social problems faced by dense, slum-like communities.

Today, the community consists of 356 men and 345 women, living in 124 households. Most community members work in the informal sector particularly in urban services, such as motorcycle taxi drivers, cleaners, and food vendors. Interestingly, one-third of community members are elderly who are also the most active among all members in running community works. Roi Krong joined the Baan Mankong programme to undergo re-blocking upgrading a decade ago; however, it has only recently engaged in the full-scale development under Baan Mankong.

Situated in Bang Chak district in the western Thonburi side of Bangkok, Sirin and Friends canalside community consists of 290 men and 430 women living in 153 households. The community was founded in 2008 as a result of the Baan Mankong programme, a participatory low-income housing programme, aggregated from several low-income communities within four nearby areas who relocated to this new site. Community members' jobs are both formal and informal.

Sangsan Nakhon Rangsit is situated in Klong Luang District of Pathum Thani Province. The community was officially created in 2012 through the Baan Mankong scheme, with the arrival of people from four different slums who had previously informally occupied land within Rangsit Municipality's limit. As many residents faced pressure from the government, as well as the poor living conditions with accumulated rubbish and smelly canals, leaders and representatives of these communities joined forces to establish a Saving and Credit Cooperative to request a Baan Mankong loan. They used this loan to buy land, build houses, and allocate permanent homes for the members. In 2016, there were 199 families living in the community. A clear majority of the community members 
are not native to Rangsit area of Pathum Thani province but migrated from 20 different provinces. Most residents can be classified as having either low or lower-middle incomes.

\begin{tabular}{|c|c|c|c|c|c|}
\hline Communities & $\begin{array}{l}\text { Number of } \\
\text { Households }\end{array}$ & $\begin{array}{l}\text { Average } \\
\text { Income }\end{array}$ & $\begin{array}{c}\text { Type of } \\
\text { Employment }\end{array}$ & $\begin{array}{c}\text { Established } \\
\text { Year }\end{array}$ & Type of Tenure \\
\hline Royklong & 124 & $\begin{array}{l}\text { More } \\
\text { than } \\
20,000 \\
\end{array}$ & $\begin{array}{c}\text { Business, Self- } \\
\text { employment, } \\
\text { Farmer } \\
\end{array}$ & - & $\begin{array}{l}\text { Baan ManKong } \\
\text { land lease }\end{array}$ \\
\hline Sirin\&Friend & 153 & $\begin{array}{l}5,000- \\
10,000 \\
\end{array}$ & Self-employment & 2008 & $\begin{array}{c}\text { Baan Mankong land } \\
\text { purchase }\end{array}$ \\
\hline Rangsit & 199 & $\begin{array}{l}\text { More } \\
\text { than } \\
20,000\end{array}$ & Self-employment & 2012 & $\begin{array}{c}\text { Baan Mankong land } \\
\text { purchase }\end{array}$ \\
\hline
\end{tabular}

Figure 1: Summary of case study communities

The household surveys totalled 193 across the three settlements, randomly selected by the field team. In Sirin \& Friends, there were 73 household surveys carried out; in Roy Klong, 70 household surveys; and in Sangsan Nakhon Rangsit (Rangsit) a total of 50 were carried out. Additionally, three focus group discussions were held, one per community, and community leaders in each settlement were interviewed. This community-level data collection was supplemented with seven key interviews carried out in various government institutions and universities involved with the settlements, including the district offices for each case study site, the Community Organisations Development Institute (CODI) which implements the Baan Mankong initiative, Ratchaphat Pranakhon University and the Research Centre for Community Development.

Limitations: We faced some challenges during the fieldwork, notably around ensuring representation of a diverse cross-section of the residents in our case study settlements. Our first points of contact were the community leaders, most of whom were women. More women than men participated in our activities. We also had the greatest representation of respondents between age of 51-70 in our survey, reflecting the demographic most likely to be at home during the day. For the focus group discussion, there was more participation by teenage youths than adults, which created challenges for the team since these children had less exposure and experience of urban community resilience, so required more guidance and examples from the field team when facilitating discussions.

Ethical issues: participants in household and key informant interviews and focus group discussions were given a verbal summary of the objectives of the research project, their rights to withdraw at any time, and were asked to give verbal consent. All data from the household survey was entered anonymously. Key informants were asked for their consent to be quoted in project reports. The focus group discussions with minors were framed in a less academic and more 'fun' manner, using narration and guidance to demonstrate academic information in a more youth-friendly manner. The team considered how to relate the research study to what the youth learnt in school or faced in daily life, however this did present more challenges for the field team who had to provide examples to draw connections between the research and the local knowledge of participants. 


\section{Results}

Our findings from the household surveys and focus group discussions suggest that certain types of crises are considered more worthy of planning for by households - and these tend to be those that have previously been experienced by the residents, particularly flooding. Additionally, crisis-response mechanisms tend to be more at the individual household level than the collective, community-level, despite the fact that all three communities had a history of collective action through the Baan Mankong initiative, suggesting that there is scope for planning approaches to build on and sustain this collective resource.

Research question one: What are existing adaptive mechanisms of households for crises?

Respondents to the household questionnaires generally demonstrated that they were able to take short-term actions to cope with the effects of a crisis. There were fewer examples of longer-term adaptive mechanisms. For the majority of respondents, coping strategies to crises consisted largely of trying to reduce their consumption of non-necessities, and being stricter in controlling their spending.

For example, in response to a flood, which the majority of respondents in all three communities had experienced, residents were able to respond by temporarily relocating to other areas, or to upper floors of their homes in Roy Klong. However, there was also a clear reliance on outside support - such as donations of food and drinking water, which is what they experienced in previous floods. Residents in Roy Klong and Sirin and Friends tried to also manage their expenses by reducing their spending, while in Rangsit respondents were more likely to use their savings to cover crisis moments. It was generally felt among respondents that trying to increase income, for example by getting a second job, was not an option during a crisis such as flooding.

In the focus group discussion in Rangsit, members stated that households do not really have plans for dealing with future crises, but this is not something they worry about. For example, in response to future flooding, they would cope by moving into the second floor of their homes. The 2011 floods hit just as they were about to start construction of their Baan Mankong homes, so they were able to modify their plans to ensure everyone built a two-storey home. During the flooding itself, most residents returned to their home villages.

With regard to water usage during a hypothetical drought, all three communities' residents explained that they would try to save water by for example, re-using grey water for watering their plants, and a number of them store water in large earth tanks, demonstrating a more forward-looking approach. Already, the majority of respondents in Sirin and Friend and Sangsan Nakhon Rangsit communities use grey water (39/69 and 25/47 respondents respectively) though in Roy Klong this proportion is smaller at 32/66 respondents.

In Sirin \& Friends community, a number of respondents suggested that better solid waste management, and selling of recyclables, was one way of generating extra income from existing resources, to help cope with financial crises. They also recognised that better solid waste management could help to reduce flooding by improving the drainage of water. However, the community leaders we interviewed stated that they were still struggling to get the whole community participating in the recycling scheme - while recyclables can be sold at 5 Baht per kilo, the leaders found it more effective to speak of this in terms of equivalence, such as free fish sauce in return for recycling bottles and paper. Most households had an awareness of the need for better income, and said they wanted to find a second job to 'save for a rainy day'. 
In Roy Klong, households generally responded that in the past they didn't feel the need to prepare especially for crises, as they had sufficient income to manage, and they were already stocking food before floods - as a form of preparation, as well as sleeping on upper floors during floods. Based on past experience, they feel that they can rely on the government, the private sector or the nearby university for support during crises - however, this reliance on external resources may be a disincentive for taking more longer-term preparatory steps ahead of crises.

Research question two: Do communities have collective resilience strategies and what role do community assets play?

Each community had previously participated in the Baan Mankong collective upgrading program, and therefore these communities have a history of collective, participatory action. However, in Roy Klong, Baan Mankong upgrading is still ongoing, in the original location (though not all households are participating), while the other two communities have completed their relocation and construction of new homes through the upgrading initiative. The current status of Baan Mankong processes within a community can affect collective action - where upgrading is still ongoing, in Roy Klong, the community efforts may be focused on completing upgrading rather than other issues such as building flood resilience or environmental management. Meanwhile, where upgrading is complete, there may be a certain weariness towards participatory approaches which could make further collective action more challenging.

In Roy Klong, there is some conflict between residents who are undergoing Baan Mankong upgrading and those that have chosen not to participate - with some households feeling pressured by community leadership to undertake upgrading and demolish their homes. Additionally, there is a clear generation gap in the community leadership structure, which is predominantly composed of older members, with younger generations being much less active. As a result of these tensions, it is not surprising that it is difficult for a collective resilience strategy to emerge on anything other than the priority topic of Baan Mankong, which also has a pressured timescale for completion.

In terms of collective responses to crises, Sirin and Friends community appears to have had the most structured approach. During the floods, community leaders played an active role in the flood response as a disaster centre was established in the community. During past severe flooding, the community set up a collective kitchen to cook using food supplied by government assistance, while those households with more resources bought in additional supplies to cook in the communal kitchen. This is a collective response that they plan to use in any future crises. This suggests that external actors such as donors or municipalities could in future support such an initiative to foster the community's social capital.

In Sangsan Nakorn Rangsit community, the residents also received support from fellow community members and highlighted the good communication channels within the settlement. The community leader in Rangsit also has previous experience of working on environmental issues, particularly around pollution of the canal water, so the residents are well informed of water pollution issues. However, the actions of the residents suggest that they are still coping more than adapting to crises, but they have had the opportunity to learn from past crises to inform future responses. Additionally, it was notable that the residents whose jobs are outside the community itself have a different perspective on flooding crises than those who remained internal to the community - they are affected in different ways, notably in terms of transport challenges. 
When asked about use of communal public space as a collective asset, all respondents felt that there was adequate provision of such space in their communities, though there was significant variation in terms of how much households used this public space. Notably, most of the public spaces they identified were outside of the settlements.

\begin{tabular}{|l|l|l|}
\hline Community & Public space & Usage \\
\hline Royklong & 1. Convenience store & 1. Shopping \\
& 2. Playground & 2. Recreation \\
& 3. University & 3. Exercise \\
& 4. Sport field & \\
\hline Sirin and & 1. Public park & 1. Recreation \\
Friend & 2. Buddhist temple & 2. Exercise \\
& 3. School & \\
& 4. Hospital & \\
\hline Rangsit & 5. Playground & 1. Recreation \\
& 1. Buddhist temple & 2. Exercise \\
& 2. School & 3. Shopping \\
& 3. Sport field & \\
\hline
\end{tabular}

However, what is public space is not always clear to households - for example, a small, fenced public garden in Sirin \& Friends was not considered by all to be 'public' and conflict over such space can affect how this collective resource can be used for the benefit of all. However, a football pitch in a neighbouring school which was previously accessible to children outside of school hours was seen as a collective resource that had been lost. This suggests that public space and its use could be considered more frequently in terms of preparing for, and responding to crises. Small community level conflicts can hamper collective action, so having clear guidelines on what, for example, is public space for all, would help to avoid this.

The responses from the surveys suggest a lack of long term planning in terms of how to use resources in the community to plan for the future, even in the case of crises that they had previously faced. There seemed to be more reliance on external support and networks - demonstrating an assumption that there will be external support, which will likely depend on the scale of the crisis. This raises the question about households' ability to plan for smaller scale disasters or slow onset disasters which might not lead to crisis response from external actors.

When households were asked about what actions they were willing to take to adapt their existing assets and resources to various crises (table 2), there seemed to be willingness to consider a number of different actions. Growing vegetables was most frequently mentioned in Sirin \& Friends community as a way to boost food resources, perhaps because this settlement is already quite green in terms of the plans households have outside their homes. In terms of investments in the houses, raising the plinths and putting in energy saving measures was the most popular option, while recycling and reusing water was seen as the easiest measure for conserving this resource. In terms of financial assets, there was a clear indication that many households wished for more of better jobs, and for training in skills to enable this happen, particularly opportunities for the elderly. Finally, there was limited interest in 
investing further financially in the community built environment, but a higher willingness to invest time towards this.

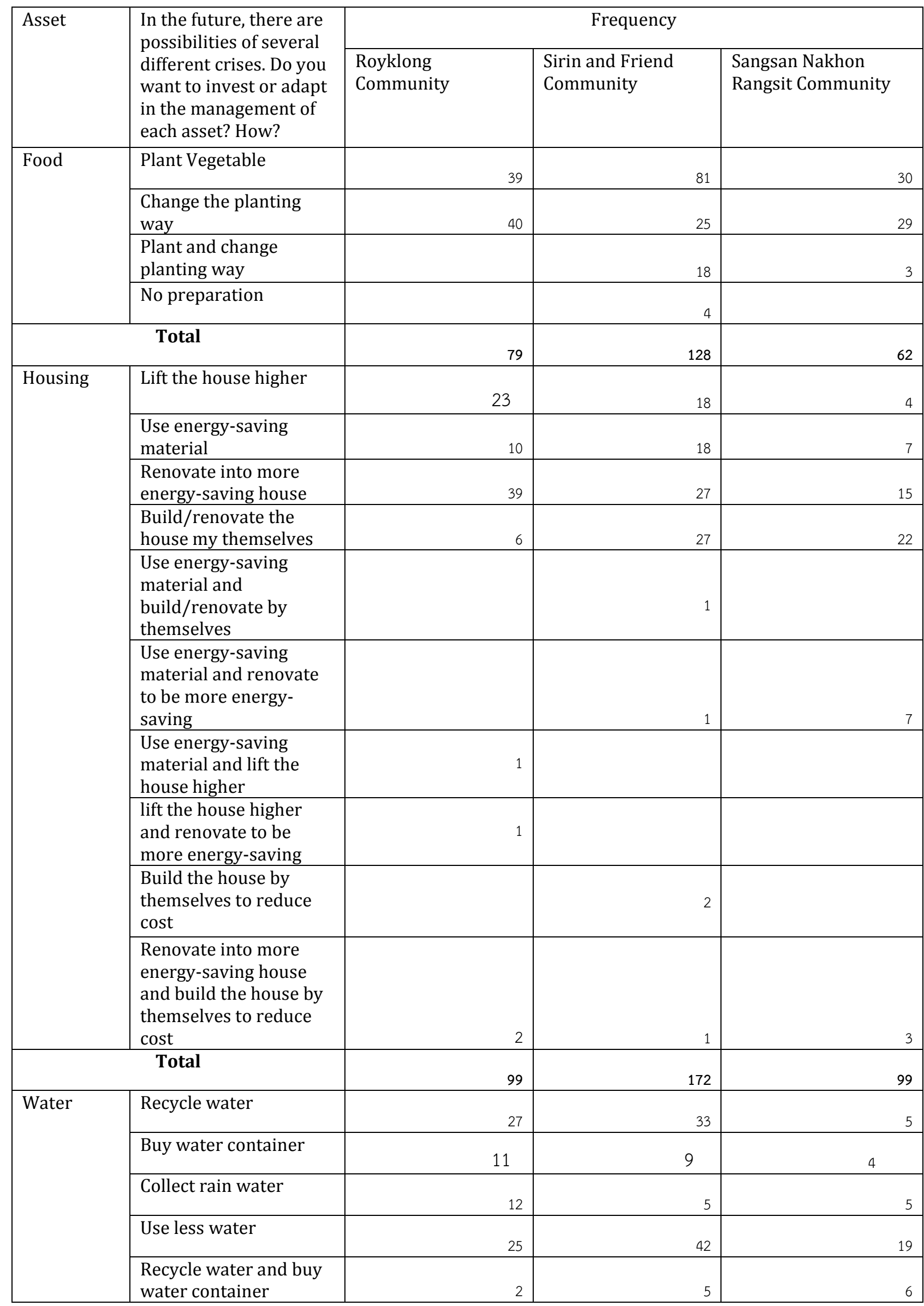




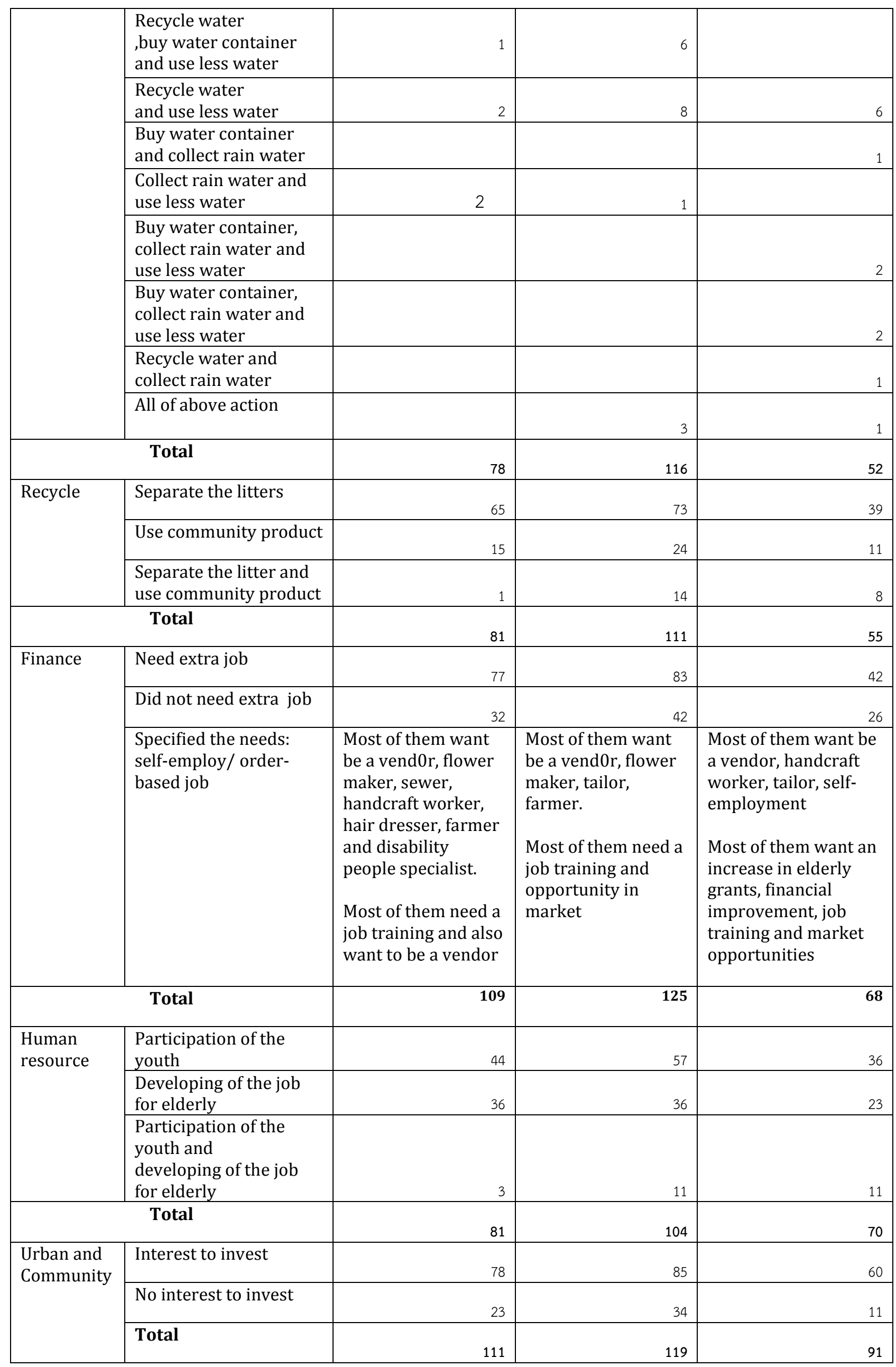




\begin{tabular}{|c|c|c|c|}
\hline \multicolumn{4}{|c|}{ Amount of money they are willing to invest THB } \\
\hline Lower than 100 & 37 & 6 & \\
\hline $101-200$ & 3 & 5 & \\
\hline $201-300$ & & 3 & \\
\hline $301-400$ & & 1 & \\
\hline $401-500$ & 6 & 15 & 10 \\
\hline More than 500 & 9 & 14 & 4 \\
\hline $\begin{array}{l}\text { Depend on individu } \\
\text { financial status }\end{array}$ & & 1 & \\
\hline Total & 55 & 44 & 29 \\
\hline Amount of time the & & & \\
\hline $\begin{array}{l}\text { Less than } 1 \\
\text { hour/day }\end{array}$ & 3 & & \\
\hline 1-5 hours/day & 22 & 18 & 17 \\
\hline 5-12 hours/day & & 10 & 4 \\
\hline All day & & & \\
\hline $\begin{array}{l}2 \text { times/week Ex. } \\
\text { weekend }\end{array}$ & 6 & 3 & \\
\hline $\begin{array}{l}\text { All day in every } \\
\text { week }\end{array}$ & 2 & 7 & \\
\hline $\begin{array}{l}\text { When they have } \\
\text { free time }\end{array}$ & & 2 & \\
\hline Total & 35 & 40 & 21 \\
\hline
\end{tabular}

Figure 2: Households' willingness to adapt in order to deal with future crises

\section{Conclusions}

Initiatives being taken at the city or municipal level can also benefit local households. For example, the leader of the social services promotion division at Rangsit Municipality explained that: "we educate people on general issue and we start with Green Building which is the plan from municipality. We receive gold medal. We start from our building and gradually acknowledged people in communities about our plan. ... They focus more on energy saving and the big picture of the office includes issue of garbage sorting, water treatment, fat filtering, waste water and energy saving campaign'. The challenge is ensuring that initiatives developed by organisations and institutions external to local communities can be integrated to these communities' existing initiatives and ways of doing things, to make the most of the collective and individual assets available at community level. They should also be adapted to the context of each community - one in the throes of upgrading may not see environmental issues as a priority, while a community that has completed upgrading may see such a campaign as an opportunity to sustain community participation. 
Our discussions with the community leaders highlighted some of the upcoming challenges in promoting participatory approaches - particularly around engaging younger generations, to ensure the sustainability of the community. At the same time, the growing number of elderly residents is another issue that needs addressing, and highlights that community priorities may be more internally focused rather than external threats such as climatic events. This also means that engaging with communities needs to be around their prioritised issues as an entry point - for example, how to ensure that there are appropriate evacuation mechanisms for less mobile residents in the event of a flood?

As Baan Mankong upgrading gets completed, community leaders involved in that process are beginning to fade out - but some leaders also feel that there is a shift away from residents coming together to resolve problems, to more of a beneficiary-style approach where residents wait for external support. There is a role here for external organisations to offer incentives for continued participatory approaches, recognising the benefits that collective action can bring in response to crises situations. As a CODI official explained 'CODI tries to push civil society mechanism which encourages the community itself to help and cope with the problem by themselves'.

However, our fieldwork also shows that households are able to cope with crises, and that there is autonomous adaptation taking place based on lived experiences. However, in terms of planning for longer term risks, there remains a lack of information and understanding around these - for example, while a flood drainage canal might be built as part of government flood-reduction measures, this still needs to take into account the ways in which patterns of flooding will change over time. This is an area where local knowledge can be used in conjunction with technical specialist knowledge and planning. District offices and municipalities also have scope to integrate community views and schemes and local knowledge into city-level plans, to reduce the disconnect between the official approaches and community and individual approaches to coping with crises in future. The Baan Mankong program could ensure that flood-proof designs are integrated as a norm in all their house and neighbourhood designs, as well as other forms of climate proofing such as natural ventilation. Again, there is a role here for CODI to provide this technical assistance

Our research demonstrates that a history of past crises, particularly flood crises, being met with provision of external relief efforts to affected communities, risks creating an expectation of future such assistance being provided, to the detriment of taking longer-term preparatory action to reduce the impact of such crises. There is an opportunity for communities to make use of their past collective action to continue this for initiatives such as drain unblocking, canal maintenance, recycling and water collection, as a means of reducing future flooding events whilst generating resources to be used in future.

\section{Acknowledgments}

This paper is part of the research supported by the funding from the UK Government's Newton Fund, the collaborative PEACE-BMR project of the International Institute for Environment and Development (IIED) and the Urban Futures Research Unit of the Faculty of Architecture and Planning at Thammasat University in Bangkok 


\section{References}

Baud, IS and Hordijk, MA, 2009. Dealing with risks in urban goernacne: what can we learn from 'resilience thinking'. The 4th Internaitonal Conference of the International Forum on Urbanism 'The New Urban Question - Urbanism beyond Neo-Liberalism', Amsterdam, Netherlands, pp 1069-1076

Bene, C, Mehta, L, McGranahan, G, Cannon, T, Gupte, J and Tanner, T, 2017. Resilience as a policy narrative: potentials and limits in the context of urban planning. Climate and Development, 10(2): $116-133$

CARE, 2009. Climate vulnerability and capacity analysis handbook. CARE. https://careclimatechange.org/wp-content/uploads/2014/12/CVCA_EN.pdf

Castan Broto, V. 2017: Urban governance and the politics of climate change. World Development, 93: 1-15; http://dx.doi.org/10.1016/j.worlddev.2016.12.031

Haque, A., D. Dodman and M. Hossain, 2014: Individual, communal and institutional responses to climate change by low-income households in Khulna, Bangladesh, Environment and Urbanization, 26(1): 112-129

Leck, H. and Simon, D., 2012. Fostering multiscalar collaboration and co-operation for effective governance of climate change adaptation. Urban Studies. DOI : 10.1177/0042098012461675

Marome,W., Pholcharoen, T., Wongpeng, N(2017). Developing and Using a Board Game as a Tool for Urban and Social Resilience and Flood Management Planning in the Bangkok Metropolitan Region. Vol 2, Issue 1, pp. 28 - 37. Urbanisation. DOI: 10.1177/2455747117708932

Marome, W (2013). Presentation: Urban Risk and Vulnerabilities of Coastal Megacity of Bangkok , this paper is part of an international research called Coastal Cities at Risk (CCaR): Building Adaptive Capacity for Managing Climate Change of Coastal Megacities (Vancouver, Manila, Lagos and Bangkok) which is funded by IDRC and three research councils of Canada.

Moench, M., F. Khan, K. MacClune, C. Amman, P. Tran, K. Hawley and the Sheltering from a Gathering Storm Research Team 2017: Transforming vulnerability: shelter, adaptation, and climate thresholds, Climate and Development 9:1, 22-35, DOI: 10.1080/17565529.2015.1067592

Moser, C (2009), Ordinary Families, Extraordinary Lives: Assets and Poverty Reduction in Guayaquil 1978-2004, Brookings Institution, Washington DC, 360 pages.

Roy, M., Hulme, D., and Jahan, F., 2013. Contrasting adaptation responses by squatters and lowincome tenants in Khulna, Bangladesh, Environment and Urbanization. 25(1). 157-176

Sattherthwaite, D, Archer, D, Colenbrander, S, Dodman, D, Hardoy, J and Patel, S, 2018, Responding to climate change in cities and in their informal settlements and economies,

Paper prepared for the IPCC for the International Scientific Conference on Cities and Climate Change in Edmonton, March 2018

Stein, A and Moser, C, 2014. Asset planning for climate change adaptation: lessons from Cartagena, Colombia, Environment and Urbanization, 26(1): 166-183 